\title{
TEM studies of hole-selective molybdenum oxide contacts in silicon heterojunction solar cells
}

Haider Ali ${ }^{1,2}$, Geoffrey Gregory ${ }^{1,2}$, Martin Bivour ${ }^{3}$, Matthew Schneider ${ }^{4}$, Martin Hermle ${ }^{3}$, Kristopher O. Davis $^{1,2}$

1. Department of Materials Science and Engineering, University of Central Florida, Orlando, FL, USA

2. Florida Solar Energy Center, University of Central Florida, Cocoa, FL, USA

3. Fraunhofer Institute for Solar Energy Systems, Heidenhofstrasse 2, D-79110 Freiburg, Germany

4. Los Alamos National Laboratory, Los Alamos, NM, USA

Silicon heterojunction (SHJ) solar cells have been able to achieve very high cell efficiencies (>25\%). This was accomplished using carrier selective contacts (CSCs) for both the electron and hole contact regions. CSCs not only passivate the silicon surface, but also allow the flow of only one type of carrier while blocking the other. Typically, CSCs consists of an intrinsic hydrogenated amorphous silicon (a-Si:H(i)) passivation layer in combination with a-Si:H(n)/a-Si:H(p), which act as electron/hole-selective contacts respectively. Recently, transition metal oxides have emerged as alternative materials to be employed as either electron-selective (e.g., $\mathrm{TiO}_{2}$ ) or hole-selective (e.g., $\mathrm{MoO}_{\mathrm{x}}, \mathrm{WO}_{\mathrm{x}}$ ) contacts in $\mathrm{SHJ}$ cells [1-3].

In the present work, the objective was to investigate the stability $\mathrm{MoO}_{\mathrm{x}}$-based hole-selective contacts upon low temperature anneal to be employed in SHJ cells. Sub-stochiometric $\mathrm{MoO}_{\mathrm{x}}$ films $(<10 \mathrm{~nm})$ were deposited by thermal evaporation from stochiometric $\mathrm{MoO}_{3}$ powder on polished $n$-type $\{100\}$ FZ-Si wafers after removal of the native $\mathrm{SiO}_{\mathrm{x}}$ by hydrofluoric acid. Then, after air exposure, indium tin oxide (ITO) was deposited by reactive sputtering to act as a transparent conducting oxide (TCO) layer. For a comparative study, an a-Si: $\mathrm{H}(i)$ buffer layer was included in certain samples prior to deposition of $\mathrm{MoO}_{\mathrm{x}}$. Finally, some samples were annealed at $200^{\circ} \mathrm{C}$ for $10 \mathrm{~min}$ on a hot plate in ambient air.

For TEM studies, specimens were prepared by focused ion beam (FIB) milling with the help of an FEI 200 TEM FIB. Cross-sectional micrographs were obtained under bright field (BF) and high-resolution transmission electron microscopy (HRTEM) conditions with the help of an FEI Tecnai F30 TEM at an operating voltage of $300 \mathrm{KV}$.

It is evident from cross-sectional micrographs that for the samples without an a-Si:H(i) buffer layer, a $\mathrm{SiO}_{\mathrm{x}}$ interlayer is formed at the $\mathrm{c}-\mathrm{Si} / \mathrm{MoO}_{\mathrm{x}}$ interface, even before annealing. Moreover, the thickness of the $\mathrm{SiO}_{\mathrm{x}}$ layer is very non-uniform. (Figure 3). The formation of $\mathrm{SiO}_{\mathrm{x}}$ likely occurs due to a chemical reaction during the deposition of $\mathrm{MoO}_{\mathrm{x}}$. Furthermore, thermodynamics are favorable for the oxidation of $\mathrm{Si}$ by $\mathrm{MoO}_{\mathrm{x}}$ since Mo has a higher affinity for oxygen than $\mathrm{Si}$, which results in a 2-4 nm thick $\mathrm{SiO}_{\mathrm{x}}$ interlayer which exceeds the maximum tunneling thickness $(\approx 2 \mathrm{~nm})$. However, $\mathrm{SiO}_{\mathrm{x}}$ is sub-stochiometric and contains defect states, such as oxygen vacancies, which allows the conduction of charge carriers and results in a high conductivity of the $\mathrm{SiO}_{\mathrm{x}}$ interlayer [4]. On the other hand, if an a-Si:H(i) buffer layer is present, then a 1-2 $\mathrm{nm} \mathrm{SiO}$ layer is observed at a-Si:H(i)/MoO interface after annealing (Figure 2); this is consistent with observations reported by Sacchetto et al. [5]

Overall, the presence of the $\mathrm{SiO}_{\mathrm{x}}$ interlayers at the c-Si/MoO $\mathrm{M}_{\mathrm{x}}$ and the a-Si:H(i)/MoO interfaces are expected to significantly impact the conduction of charge carriers through c-Si/MoO $/$ /TTO and c-Si/a- 
$\mathrm{Si}: \mathrm{H}(i) / \mathrm{MoO}_{\mathrm{x}} / \mathrm{ITO}$ contact structures, respectively. Their band alignment and the presence of defect states within the $\mathrm{MoO}_{\mathrm{x}}$ layer (e.g., oxygen vacancies) will be investigated in detail as part of this study.

In conclusion, TEM studies have successfully revealed oxygen diffusion across the interfaces and formation of a sub-stochiometric $\mathrm{SiO}_{\mathrm{x}}$ interlayer at the c-Si/MoO $\mathrm{M}_{\mathrm{x}}$ and $\mathrm{a}-\mathrm{Si}: \mathrm{H}(i) / \mathrm{MoO}_{\mathrm{x}}$ interfaces. Furthermore, no interlayer was observed at the $\mathrm{MoO}_{\mathrm{x}} / \mathrm{ITO}$ interface, even after annealing. This work has provided valuable information about the stability of the $\mathrm{MoO}_{\mathrm{x}}$-based hole-selective front contacts employed in high-efficiency SHJ solar cells.

\section{References}

[1] H. Ali, X. Yang, K. Weber, W.V. Schoenfeld, K.O. Davis, Microscopy and Microanalysis 23 (2017) 900-904.

[2] X. Yang, Q. Bi, H. Ali, K. Davis, W.V. Schoenfeld, K. Weber, Advanced Materials 28 (2016) 5891-5897.

[3] M. Bivour, J. Temmler, H. Steinkemper, M. Hermle, Solar Energy Materials and Solar Cells 142 (2015) 34-41.

[4] L.G. Gerling, C. Voz, R. Alcubilla, J. Puigdollers, Journal of Materials Research 32 (2016) 260-268.

[5] D. Sacchetto, Q. Jeangros, G. Christmann, L. Barraud, A. Descoeudres, J. Geissbühler, M. Despeisse, A. Hessler-Wyser, S. Nicolay, C. Ballif, IEEE Journal of Photovoltaics 7 (2017) 1584-1590.

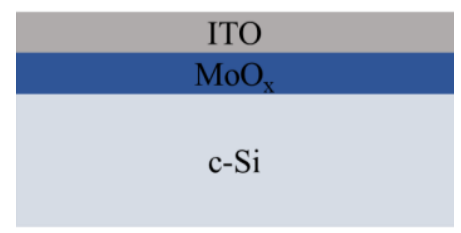

(a)

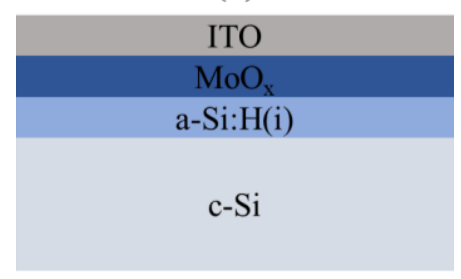

(b)

Figure 1: Schematic of test structures

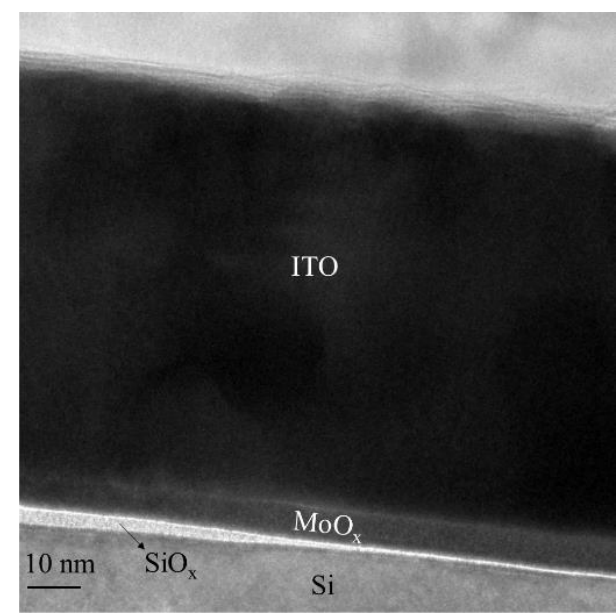

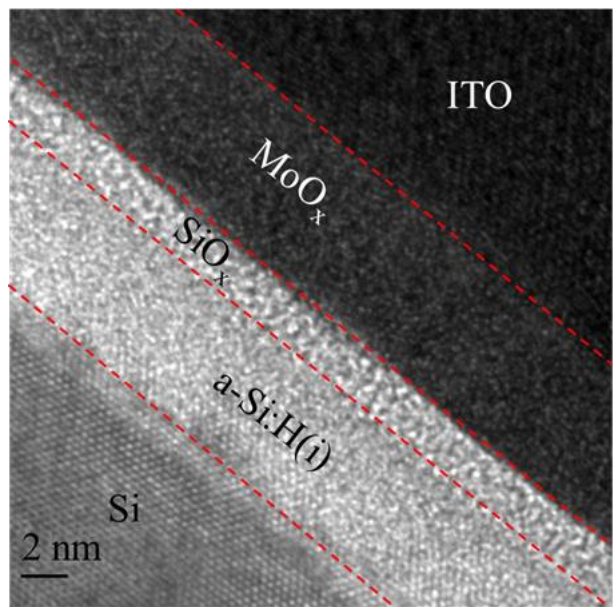

Figure 2: HRTEM image of c-Si/a-Si:H(i)/MoO ${ }_{x} / \mathrm{ITO}$ (annealed)

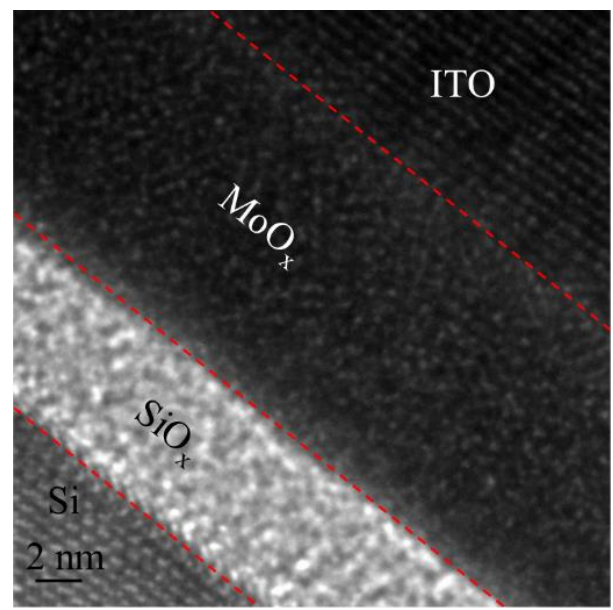

Figure 3: BF (left) and HRTEM (right) images of c-Si/MoO $/$ /TO (as-deposited) 